\title{
Primary intraosseous squamous cell carcinoma arising in dentigerous cyst: Report of 2 cases and review of the literature
}

\author{
Cosme Gay-Escoda ${ }^{1}$, Octavi Camps-Font ${ }^{2}$, Marta López-Ramírez ${ }^{3}$, August Vidal-Bel ${ }^{4}$
}

${ }^{1} \mathrm{MD}$, DDS, MS, PhD. Chairman and Professor of Oral and Maxillofacial Surgery. Faculty of Dentistry - University of Barcelona. Director of the Master of Oral Surgery and Implantology (EFHRE International University/FUCSO). Coordinating investigator of the IDIBELL institute. Head of the Department of Oral and Maxillofacial Surgery and Implantology, and Director of the TMJ Disease and Orofacial Pain Unit. Teknon Medical Center. Barcelona, Spain

${ }^{2}$ DDS. Fellow of the Master degree program in Oral Surgery and Implantology. Faculty of Dentistry - University of Barcelona

${ }^{3}$ DDS, MS. Master degree program in Oral Surgery and Implantology. Faculty of Dentistry - University of Barcelona

${ }^{4}$ MD. Specialist in Clinical Pathological Anatomy. Associate Professor of Experimental Clinical Pathology and Terapeutics. School of Dentistry of the University of Barcelona. Researcher of the IDIBELL Institute. Barcelona, Spain

Correspondence:

Centro MédicoTeknon

Instituto de Investigación IDIBELL

C/Vilana 12

08022 - Barcelona, España

cgay@ub.edu

Received: 26/07/2015

Accepted: 05/09/2015

Gay-Escoda C, Camps-Font O, López-Ramírez M, Vidal-Bel A. Primary intraosseous squamous cell carcinoma arising in dentigerous cyst: Report of 2 cases and review of the literature. J Clin Exp Dent. 2015;7(5):e66570.

http://www.medicinaoral.com/odo/volumenes/v7i5/jcedv7i5p665.pdf

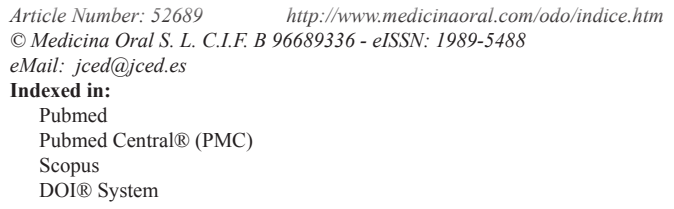

\begin{abstract}
Dentigerous cysts are one of the most common odontogenic cysts of the oral cavity. Odontogenic cysts can give rise to a variety of neoplasms. Carcinoma arising in a dentigerous cyst is extremely rare, with a review of literature showing near 30 cases. The present report describes 2 cases of primary intraosseous squamous cell carcinoma originated from a dentigerous cyst. The first one refers to a 57-year old female with a persistent lesion in the left retromolarregion and diagnosed with squamous cell carcinoma originated fromthe incomplete excision of the lower third molar follicle during its surgical extraction. The second case describes the case of an 18-year old male with an impacted upper canine with previous history of infection and swelling of the oral cavity. The histopathological study revealed the malignization of the follicle surrounding the dental crown. These two cases confirmed the importance of the histopathological study of all the tissue samples obtained from surgical procedures. Although the development of a malignant lesion from a dentigerous cyst is rare and its clinical-radiological features are apparently innocuous, this entity should be considered as a differential diagnosis.
\end{abstract}

Key words: Dentigerous cyst, odontogenic cyst, squamous cell carcinoma, primary intraosseous squamous cell carcinoma, odontogenic carcinoma.

\section{Introduction}

Primary intraosseousodontogenic carcinoma (PIOC) is defined as a squamous cell carcinoma arising within the jawbones; without any initial connection with the oral mucosa or sinus mucosa and develops from remnants of odontogenic epithelium (1).
The term PIOC had been suffered several modifications since was firstly suggested by the World Health Organization (WHO) in 1972 (2). In fact, the use of the term PIOC is considered inappropriate since Eversole et al. (3) used the term primary intraosseous squamous cell carcinoma (PIOSCC) to replace it. According to the la- 
test WHO Classification of Tumours classification there are three PIOSCCs subtypes (3):

1. Solid tumour that invades marrow spaces and induces osseous resorption

2. PIOSCC arising from the lining of an odontogenic cyst, making a subdivision in carcinomas arising in a keratocystic odontogenic tumuor ('keratocyst') and carcinomas arising in other odontogenic cysts

3. PIOSCC in association with other benign epithelial odontogenic tumours

The malignant transformation of an odontogenic cyst into a PIOSCCis extremely rare; there are nearly 100 cases in the literature (1). Most of them arise from radicular/residual cysts $(60 \%)$, although cases originated from dentigerous cysts $(16 \%)$, keratocystic odontogenic tumour $(14 \%)$ and lateral periodontal cysts (1\%) have been also reported $(1,4)$.

The definitive diagnosis of PIOSCC is often difficult and usually made in retrospect due to lack of pathognomonic symptoms and radiographic changes. Differential diagnosis includes alveolar carcinomas that have invaded the bone from the overlying soft tissue, from tumours that have metastasized to the jaw from distant sites, from association with some other odontogenictumor, and also from tumors of the maxillary sinus (5).

The aim the present report is to describe the clinical features, therapeutic management and follow-up of two cases of PIOSCC arising indentigerous cysts. The study protocol was approved by the Ethical Committee for Clinical Research (CEIC) of the Dental Hospital of the University of Barcelona.

\section{Case Report}

-Case Report 1

In 1988, a57 year-old female came to the Oral Surgery Unit of the School of Dentistry of the University of Barcelona with anexophytic tumour-like lesion after six-month evolution. Patient's pathological background comprised stomach, controlled with omeprazole $20 \mathrm{mg}$ orally (1 every 12 hours. (Omapren ${ }^{\circledR}$, Lesvi, Sant Joan Despí, Spain)). The patient visited her private dental practitioner presenting left submaxillary region swellingrelated to homolateral third molar impaction. The lower second and third left molars were removed, although there is no information regarding the complete excision of the pericoronary lesion as no histopathological examination was carried out. Four weeks after the surgical procedure, patient continued topresent slight swelling and trismus. Three moths latter, due to symptoms persistence, curettage and cleaning of the area was carried out without a histopathological examination of the removed tissue.

General and regional exploration revealed facial swelling on the left side, slight trismus with neither nerve function impairment nor associated adenopathies. Intraoral examination showed an exophytic tumour-like lesion in there tromolar region. Panoramic X-ray revealed a radiolucent lesion with uneven margins and indents (Fig. 1).

Based on the data obtained, a tentative diagnosis of PIOSCC was established.

Once informed consent was accepted, an incisional biopsy of the osteolytic lesion was performed. The histopathological examination revealed a squamous carcinoma arising in adentigerous cyst. The lesion was covered by stratified squamous epithelium with maturation of keratinocytes and no atypia. Squamous cells and cytologicatypia were noted focally infiltrating the stroma (Fig. 2).

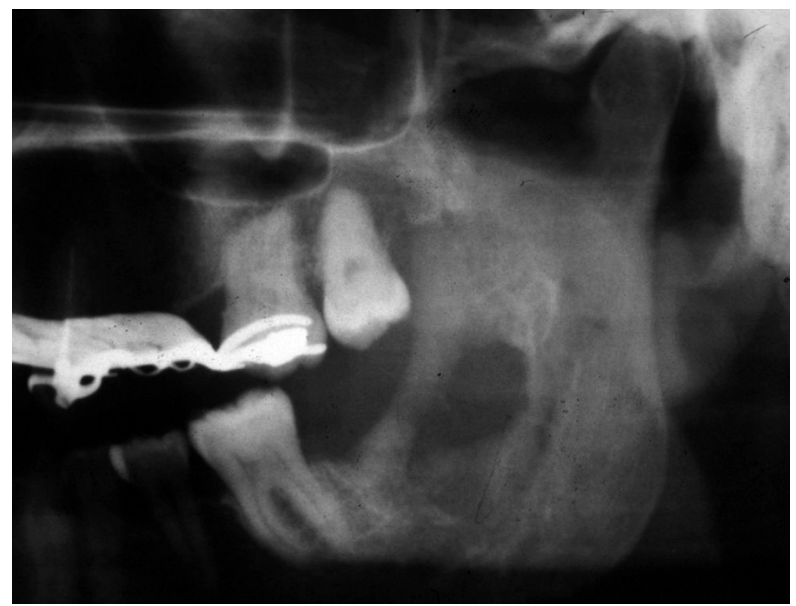

Fig. 1. Case report 1. Panoramic X-ray at 4 months after surgical extraction of the lower left second and third molars.

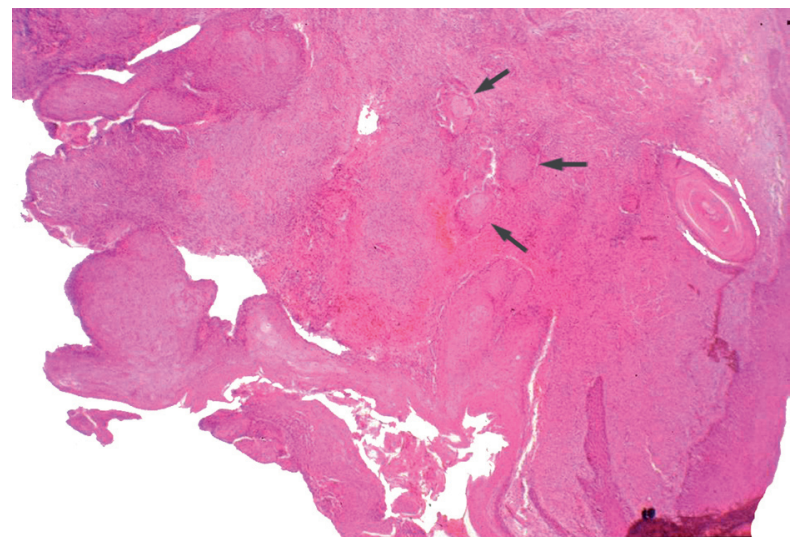

Fig. 2. Case report 1. Histological image where squamous cells and cytologicatypia were focally infiltrating the stroma.

On August 1988, once the Head and Neck Tumour Board reviewed the case, preoperative chemotherapy was administered: one single dose of cistaplin (100 $\left.\mathrm{mg} / \mathrm{m}^{2}\right)$ and tegafur $\left(1000 \mathrm{mg} / \mathrm{m}^{2} /\right.$ daily) during 2 weeks. Three months later supraomohyoid neck dissection was performed together with hemimandibulectomy to the mental foramen, including the inferior alveolar ner- 
ve. The histological study of the cervical lymph nodes, submaxillary glands and the resected tooth showed no malignant invasion.

No postoperative complications were reported. Since then, clinical and radiological follow-up appointments were scheduled every six months, and no evidence of recurrence was found until 1991. As the evolution was favourable, the patient was offered to reconstruct the left posterior region of the mandible using a microvascularized skin engraftment. However the proposed treatment was rejected since the functional and aesthetic sequelae were well tolerated. Follow-up visits have been performed at yearly interval with no recurrence.

-Case report 2

In 2004, an 18 year-old male without pathological backgroundwas referred to the Oral Surgery Unit of the School of Dentistry of the University of Barcelona presenting recurrent painful inflammation of the right canine space. Patient's dental practitioner performed a surgical debridement of the lesion two weeks before. As purulent drainage and pain were reported, amoxicillin $875 \mathrm{mg}$ and potassium clavulanate $125 \mathrm{mg}$ (p.o every 8 hours for 7 days (Augmentine 875/125; GlaxoSmithKline; Madrid, Spain)) and ibuprofen $600 \mathrm{mg}$ (p.o. every

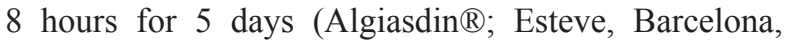
Spain)) were prescribed.

Extraoral and regional examination revealed swelling in the right canine's fossa, painful to palpation with soft and tender but not fluctuating consistency. Regarding local examination, the oral mucosa showed congestion without ulceration and an active fistulous tract was observed. Furthermore, the presence of the upper temporary canines was also noted (Fig. 3).

Panoramic X-ray revealed impaction of both permanent canines with unilocular well-defined radiolucent image surrounding its crowns. Both upper right first premolar and temporary canine showed root resorption, although $\mathrm{CO}_{2}$ vitality tests were un event ful (Fig. 4).

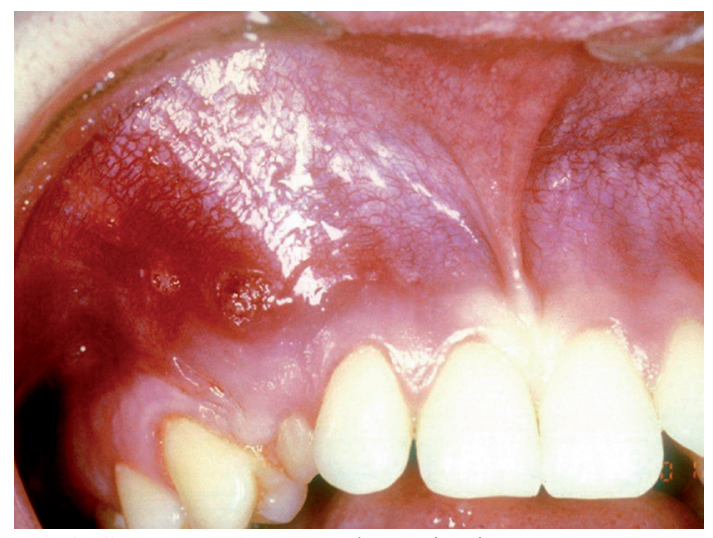

Fig. 3. Case report 2. Intraoral examination.

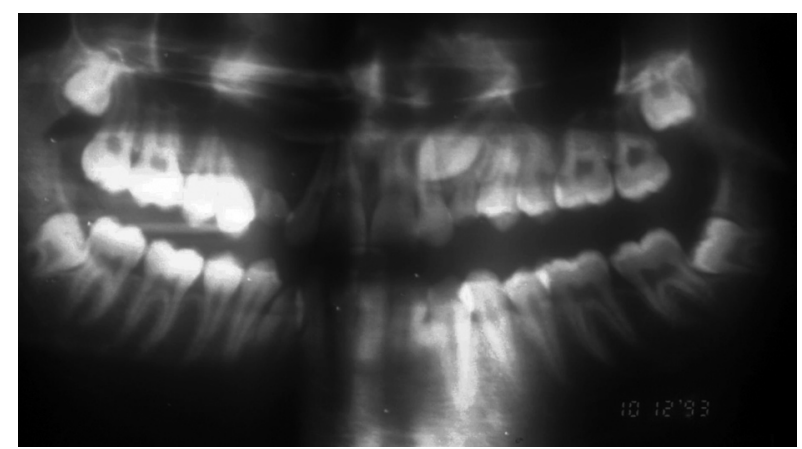

Fig. 4. Case report 2. Panoramic X-ray showing the impaction of the upper right canine associated with unilocular radiolucency surrounding the crown.

Based on the data obtained, presumptive diagnoses of infected and non-infected dentigerous cysts associated with the upper permanent canines were respectively established.

Once informed consent was accepted, locoregional anaesthesia (articaine in a 4\% solution with epinephrine 1:100,000 (Artinibsa ${ }^{\circledR}$; Inibsa Dental, Lliçà de Vall, Spain)) techniques were employed for the extraction of the upper right temporary and permanent canines and the associated lesion using a buccal approach.

Tissue samples obtained were sent to its histopathologic analyses. The results showed a cystic cavity covered by stratified squamous epithelium with marked papillomatosis and acantholysis. In the areas where the acantholytic type was larger, an alteration on keratinocyte maturation and cytologicatypia infiltrating the stroma were observed (Fig. 5). Based on these findings, diagnosis of squamous cell carcinoma a rising in a dentigerous cyst was obtained.

After malignant diagnosis, the patient was referred and treated in the Oral and Maxillofacial Service at the Bellvitge University Hospital. General anesthesia was used to perform the partial resection of upper right maxilla from central incisor to second premolar. No neoplastic infiltration was noted. Reconstruction was carried out with autogenous bone grafts obtained from the iliac crests and titanium plates during the same surgical procedure. No postoperative complications were reported (Fig. 6).

After one year, as no recurrence was observed four dental implants (Nobel Speedy Groovy ${ }^{\circledR}$; Nobel Biocare, Zurich, Switzerland) were placed in order to rehabilitate the edentulous span.

Follow-up visits have been performed every 6 months with no recurrence of the malignant lesion. However, in 2010, one implant failed due to peri-implantitis. Actually, the prosthesis is supported by three successful implants.

\section{Discussion}

The epithelial lining of odontogenic cysts may experience simple cystic expansion, keratinization, mucous 

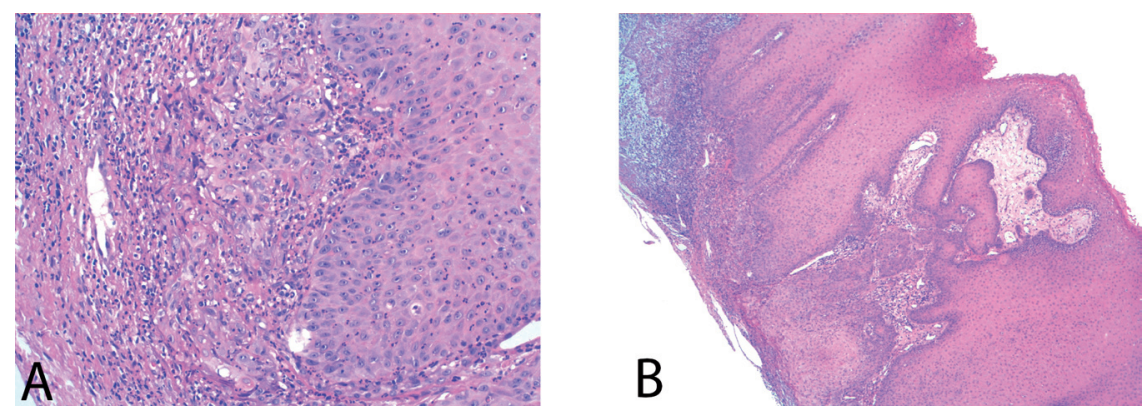

Fig. 5. A) Infiltration areas: cytologicatypia was noted focally infiltrating the stroma (HE, x200). B) Cyst wall covered by squamous epithelium showing hyperplasia and infiltrated carcinoma (upper angle) (HE, x40).

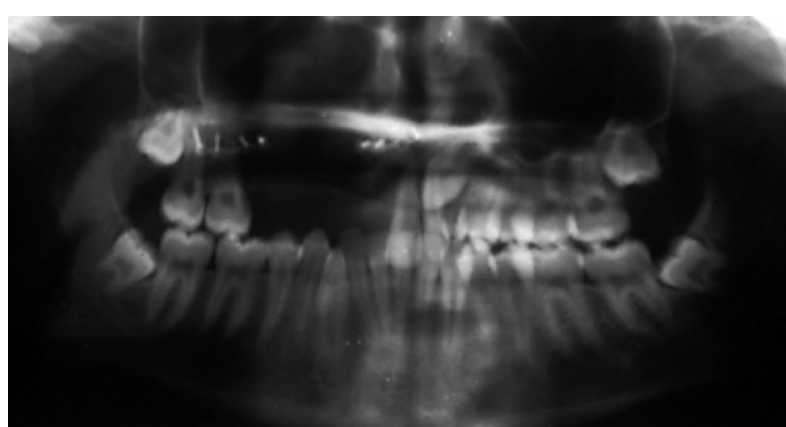

Fig. 6. Case report 2. Panoramic X-ray after bone grafts from iliac crests fixed with titanium plates.

prosoplasia, or dysplastic transformation (6). The most common neoplasms arising inodontogenic cysts are benign tumours such as the odontogenic adenomatoid tumour, pleomorphic adenoma, as well as serve as a precursor of an ameloblastoma (7). Although very unlikely, malignant transformation of an odontogenic cyst into a PIOSCC may occur, most of them arise in radicular/residual cysts, followed by dentigerous cysts, keratocysticod ontogenic tumour and lateral periodontal cysts $(1,4)$.

The real pathogenesis of PIOSCC still remains unclear. Nevertheless, it has been suggested that the longstanding chronic inflammation might be the main predisposing factor to induce a malignant transformation in the cyst epithelium $(8,9)$. Bodner et al. (1) suggested three main mechanisms by which inflammation can initiate and promote carcinogenesis:

- Chronic inflammation is often accompanied by the formation of reactive oxygen and nitrogen species by phagocytes. These have the potential to damage DNA, proteins, and cell membranes, modulate enzyme activities and gene expression, promoting carcinogenesis. Moreover, chronic inflammation appears to promote apoptosis of normal cells that leads to a compensatory proliferative response by the remaining cells. This process increases the number of cells that are dividing and therefore are subject to DNA damage and promotes the growth of malignant cells.
- Infectious agents may directly transform cells by inserting active oncogenes into the host genome, inhibiting tumour suppressor or stimulating mitoses.

- Infectious agents may induce immunosuppression with consequent reduced immunosurveillance.

Genetic factors have been also suggested to play a role in the carcinogenesis initiation and progression. In this sense, recent studies suggest that there is a relationship between the epidermal growth factor receptor distribution in pericoronal follicles and the origin of odontogenic cysts and tumors (10).

A review of the literature from a total of 30 cases, including our report, on PIOSCC originated from dentigerous cysts was performed in order to summarize the main clinical features, treatment options and prognosis of this entity $(5,7,11-35)$ (Table 1$)$. Dentigerous cyst malignization into PIOSCC mostly occurs from the 3rd decade of life; the male to female ratio was 2.3:1. Male gender predilection it not has to be considered as to PIOSCC but rather reflects the higher pre-existing occurrence of odontogenic cysts among men (36).

Clinically, according to the typical features of non-infected dentigerous cysts, PIOSCC appears to be painless in the majority of cases (37). Nevertheless, in case of clinical manifestations appearance, swelling was the most frequent sign (43.4\%), followed by pain $(13.3 \%)$ and nerve impairment $(10.0 \%)$. The mandible was involved in most of the cases $(86.7 \%)$.

PIOSCC's radiological features are apparently innocuous; showing a unilocular cystic-like radiolucency, varying in size, shape and margins. Occasionally it may also present a multilocular aspect (38). In other cases, the margins are irregular or poorly defined $(10,22)$.

The definitive diagnosis of PIOSCC is often difficult and usually made in retrospect due to lack of pathognomonic symptoms and radiographic changes. In any case, this fact forces to perform a routinely accurate anamnesis and physical examination and complementary tests-computed tomography and/or magnetic resonance, chest imagingand biopsy- as may be necessary to ensure the benign nature of the lesion. Moreover, in advanced 
Table 1. Summary of the main clinical, therapeutic and prognostic features of the 30 cases of PIOSCC arising indentigerous cysts reported (5,7,11-35).

\begin{tabular}{|c|c|c|c|}
\hline \multicolumn{2}{|l|}{ Age } & \multicolumn{2}{|l|}{ Treatment } \\
\hline $0-2$ decade & $4(13.3 \%)$ & Surgery & \\
\hline 3-5 decade & $12(40.0 \%)$ & Alone & $22(73.3 \%)$ \\
\hline 6-8 decade & $14(46.7 \%)$ & Surgery+Radiotherapy & $4(13.3 \%)$ \\
\hline \multicolumn{2}{|l|}{ Gender } & Surgery + Radiotheraphy + Chemotherapy & $3(10.0 \%)$ \\
\hline Male & $21(70.0 \%)$ & Surgery + Chemotherapy & $1(3.3 \%)$ \\
\hline Female & $9(30.0 \%)$ & Radiotherapy & $1(3.3 \%)$ \\
\hline \multicolumn{2}{|l|}{ Location } & Neck dissection & $17(56.7 \%)$ \\
\hline Maxilla & $4(13.3 \%)$ & \multicolumn{2}{|l|}{ Histologic differentiation } \\
\hline Mandible & $26(86.7 \%)$ & Poor & $3(10.0 \%)$ \\
\hline \multicolumn{2}{|l|}{ Signs \& Symptoms } & Moderate & $9(30.0 \%)$ \\
\hline Asymptomatic & $8(26.7 \%)$ & Well & $15(50.0 \%)$ \\
\hline Mass & $5(16.7 \%)$ & Carcinoma in situ & $1(3.3 \%)$ \\
\hline Pain & $4(13.3 \%)$ & \multicolumn{2}{|l|}{ Adenopathy or Metastases } \\
\hline Asymptomatic mass & $8(26.7 \%)$ & Yes & $10(33.3 \%)$ \\
\hline Expansion & $2(6.7 \%)$ & No & $20(66.6 \%)$ \\
\hline \multirow[t]{3}{*}{ Nerve impairment } & \multirow[t]{3}{*}{$3(10.0 \%)$} & \multicolumn{2}{|l|}{ Survival } \\
\hline & & 2 years & $11(64.7 \%)$ \\
\hline & & 5 years & $2(28.6 \%)$ \\
\hline
\end{tabular}

cases, positron emission tomography is mandatory to assessganglionar involvement, distant metastases, and synchronous second primary tumors (28).

Due its low incidence and the absence of neither clinical nor radiological pathognomonic features; initial treatment is lesion enucleation in all of the cases. Once the histopathological examination is concluded treatment approach for PIOSCC should be determined by the extent of the carcinoma (6). In this sense, a second and more radical treatment may be necessary by means of surgical resection together with radio and/or chemotherapy if the margins of the tumour are positive or there is carcinoma in the surrounding bone $(7,22)$. According to our findings, most of cases required partial hemimandibulectomy or maxillectomy (73.3\%) in conjunction with neck dissection (56.7\%) to ensure the complete removal of the primary lesion (Table 1).

Fortunately, neck metastases from PIOSCC are rare (1). Our results are in accordance with these findings since in two-thirds of the cases neither ganglionar nor metastatic affection was reported (Table 1). Neck metastasis is an important prognostic factor and perhaps affects survival; in such advanced head and neck squamous cell carcinomas immunotherapy is an emerging therapeutic option. In this regard, the monoclonal antibody cetuximabin conjunction with radiotherapy may improve survival rates of recurrent or metastatic cases (39).
The majority of cases of PIOSCC are associated with a well or moderately differentiated squamous cell carcinomas (1). Our results agree with those findings because $80 \%$ of the reviewed cases had these histopathologic differentiation (Table 1).

The overall survival rate of patients with a PIOSCC was $64.7 \%$ and $28.6 \%$ at 2 and 5 years, respectively (Table 1 ). Squamous cell carcinoma arising in a dentigerous cyst is extremely rare. Due to the fact that malignant transformation occurs unnoticed from both medical and radiological features, complete excision and routine histopathological studies are mandatory. Some patients reporting apparently banal radiographs and symptoms may be carriers of potentially malignant lesions. Future similar cases should be published in order to obtain more information on this rare entity.

\section{References}

1. Bodner L, Manor E, Shear M, van der Waal I. Primary intraosseous squamous cell carcinoma arising in anodontogeniccyst: a clinicopathologicanalysis of 116 reported cases. J Oral PatholMed. 2011;40:733-8.

2. Pindborg JJ, Kramer IRH, Torloni H. Histologic typing of odontogenic tumours, jaw cysts and allied lesions. Geneva: World Health Organization, 1972.

3. Eversole LR, Siar CH, van der Waal I. Primary intraosseous squamouscell carcinomas. In: Barnes L, Evson JW, Reichart P, Sidransky D, eds. World Health Organization classification of tumors. Pathology and genetics head and necktumors. World Health Organization International Agency for Researchon Cancer. Lyon: IACR Press, 
2005;290-1

4. Baker RD, D'Onofrio ED, Corio RL, Crawford BE, Terry BC. Squamous-cell carcinoma arising in a lateral periodontal cyst. Oral Surg Oral Med Oral Pathol. 1979:47:495-9.

5. Charles M, Barr T, Leong I, Ngan BY, Forte V, Sandor GK. Primary intraosseous malignancy originating in an odontogenic cyst in a young child. J Oral Maxillofac Surg. 2008:66:813-9.

6. Makowski GJ, McGuff S, Van Sickels JE. Squamous cell carcinoma in a maxillary odontogenickeratocyst. J Oral Maxillofac Surg. 2001;59:76-80.

7. Yasuoka T, Yonemoto K, Kato Y, Tatematsu N. Squamouscell carcinoma arising in a dentigerouscyst. J Oral Maxillofac Surg. 2000;58:900-5.

8. Schwimmer AM, Aydin F, Morrison N. Squamous cell carcinoma arising in residual odontogenic cyst: report of a case and review of literature. Oral Surg Oral Med Oral Pathol. 1991;72:218-21.

9. Gardner AF. The odontogenic cyst as a potential carcinoma; a clinico-pathologic appraisal. J Am Dent Assoc. 1969;78:746-55.

10. Da Silva Baumgart C, da Silva Lauxen I, Filho MS, de Quadros OF. Epidermal growth factor receptor distribution in pericoronal fo1licles: Relationship with the origin of odontogenic cysts and tumors. Oral Surg Oral Med Oral Pathol Oral Radiol Endod. 2007;103:240-5. 11. Bradfield WJ, Broadway ES. Malignant change in a dentigerous cyst. Br J Surg. 1958;45:657-9.

12. Williams IE, Newman CW. Squamous-cell carcinoma associated with a dentigerous cyst of the maxilla. Review and report of a case. Oral Surg Oral Med Oral Pathol. 1963;16:1012-6.

13. Kramer HS, Scribner JH. Squamous-cell carcinoma arising in a dentigerous cyst. Report of a case. Oral Surg Oral Med Oral Pathol. 1965;19:555-61.

14. Angelopoulos AP, Tilson HB, Stewart FW, Jaques WE. Malignant transformation of the epithelial lining of the odontogenic cysts. Report of a case. Oral Surg Oral Med Oral Pathol. 1966;22:415-28.

15. Lee KW, Loke SJ. Squamous cell carcinoma arising in a dentigerous cyst. Cancer. 1967;20:2241-4.

16. Fanibunda K, Soames JV. Malignant and premalignant change in odontogenic cysts. J Oral Maxillofac Surg. 1995;53:1469-72.

17. Lapin R, Garfinkel AV, Catania AF, Kane AA. Squamous cell carcinoma arising in a dentigerous cyst. J Oral Surg. 1973;31:354-8.

18. Norris LH, Baghaei-Rad M, Maloney PL, Simpson G, Guinta J. Bilateral maxillary squamous odontogenic tumors and the malignant transformation of a mandibular radiolucent lesion. J Oral Maxillofac Surg. 1984;42:827-34.

19. Van der Waal I, Rauhamaa R, Van der Kwast WA, Snow GB. Squamous cell carcinoma arising in the lining of odontogenic cysts. Report of 5 cases. Int J Oral Surg. 1985;14:146-52.

20. Bradley N, Thomas DM, Antoniades K, Anavi Y. Squamous cell carcinoma arising in an odontogenic cyst. Int J Oral Maxillofac Surg. 1988;17:260-3.

21. Berenholz L, Gottlieb RD, Cho SY, Lowry LD. Squamous cell carcinoma arising in a dentigerous cyst. Ear Nose Throat J. 1988;67:764-8.

22. Maxymiw WG, Wood RE. Carcinoma arising in a dentigerous cyst: A case report and review of the literature. J Oral Maxillofac Surg. 1991;49:639-43.

23. Johnson LM, Sapp JP, McIntire DN. Squamous cell carcinoma arising in a dentigerous cyst. J Oral Maxillofac Surg. 1994;52:987-90.

24. Copete MA, Cleveland DB, Orban RE, Jr Chen SY. Squamous carcinoma arising from a dentigerous cyst: Report of a case. Compend Contin Educ Dent. 1996;17:202-4.

25. McDonald AR, Pogrel MA, Carson J, Regezi J. P53-Positive squamous cell carcinoma originating from an odontogenic cyst. J Oral Maxillofac Surg. 1996;54:216-8.

26. Manganaro AM, Cross SE, Startzell JM. Carcinoma arising in a dentigerous cyst with neck metastasis. Head Neck. 1997;19:436-9.

27. Roofe SB, Boyd EM Jr, Houston GD, Edgin WA. Squamous cell carcinoma arising in the epithelial lining of a dentigerous cyst. South Med J. 1999;92:611-4.

28. Gulbranson SH, Wolfrey JD, Raines JM, McNally BP. Squamous cell carcinoma arising in a dentigerous cyst in a 16-month-old girl. Otolaryngol Head Neck Surg. 2002;127:463-4.

29. Scheer M, Koch AM, Drebber U, Kubler AC. Primary intraosseous carcinoma of the jaws arising from an odontogenic cyst-a case report. J Craniomaxillofac Surg. 2004;32:166-9.

30. Olson JW, Miller RL, Kushner GM, Vest TM. Odontogenic carcinoma occurring in a dentigerouscyst: case report and clinicalmanagement. J Periodontol. 2000;71:1365-70.

31. Shimoyama T, Ide F, Horie N, Kato T, Nasu D, Kaneko T, et al. Primaryintraosseous carcinoma associated with impacted third molar of themandible: review of theliterature and report of a new case. J Oral Sci. 2001;43:287-92.

32. Elo JA, Slater LJ, Herford AS, Tanaka WK, King BJ, Moretta CM. Squamous cell carcinoma radiographically resembling a dentigerous cyst: Report of a case. J Oral Maxillofac Surg. 2007;65:2559-62.

33. Cillo JE Jr, Ellis E 3rd, Kessler HP. Pericoronalsquamousodontogenic tumor associatedwithanimpacted mandibular third molar: a case report. J Oral Maxillofac Surg. 2005;63:413-6.

34. Colbert S, Brennan PA, Theaker J, Evans B. Squamouscell carcinoma arising in dentigerouscysts. J Craniomaxillofac Surg. 2012;40:355-7.

35. Zapała-Pośpiech A, Wyszyńska-Pawelec G, Adamek D, Tomaszewska R, Zaleska M, Zapała J. Malignant transformation in the course of a dentigerous cyst: a problemfor a clinician and a pathologist. Considerations based on a case report. Pol J Pathol. 2013;64:64-8.

36. Manor E, Kachko L, Puterman MB, Szabo G, Bodner L. Cysticlesions of thejaws - a clinic pathological study of 322 cases and review of the literature. Int J Med Sci. 2012;9:20-6.

37. Eversole LR. Malignant epithelialod ontogenic tumors. Semin Diagn Pathol. 1999;16:317-24.

38. Gardner AF. A survey of odontogenic cysts and their relationship to squamous cell carcinoma.Dent J. 1975;41:161-7.

39. Schutt C, Bumm K, Mirandola L, Bernardini G, D’Cunha N, Tijani $\mathrm{L}$, et al. Immunological treatment options for locoregionally advanced head and neck squamous cell carcinoma. 2012;31:22-42.

\section{Conflict of interests}

The authors declare that there are no conflicts of interest in this study.

Acknowledgments

This study was performed by the "Dental and Maxillofacial Pathology and Therapeutic" research group of the IDIBELL Institute. 